\section{DEJANDO ATRÁS LAS FRONTERAS. LAS POLÍTICAS MIGRATORIAS ANTE LAS EXIGENCIAS DE LA JUSTICIA GLOBAL}

\author{
Juan Carlos Velasco \\ Instituto de Filosofía - CSIC (Madrid)
}

\section{LEAVING FRONTIERS BEHIND. MIGRATION POLICIES IN VIEW OF THE REQUIREMENTS OF GLOBAL JUSTICE}

\begin{abstract}
This article deals with the reciprocal normative implications between the conceptions of global justice and citizenship on the one hand, and the definition of migration politics on the other hand. The investigation is carried out in four steps: first, there will be provided some reasons to overcome the state oriented focus of the theory of justice; then the worldwide poverty and the migration flows will be pointed out as problems that any modern theory of justice has to cope with; in a third step, it will be shown to what extent the national borders have to be regarded as obstacles for an implementation of a global conception of justice; and, finally, it will be argued for a redefinition of the notion of citizenship that is meant to build the normative horizon of migration politics.
\end{abstract}

KEY WORDS: Global justice; theory of justice; human rights; Rawls; migrations; migration politics; citizenship; borders; world poverty; national State; globalization.

Las políticas públicas destinadas a gestionar el complejo fenómeno migratorio encuentran no sólo una enorme resonancia en la esfera pública de las sociedades receptoras, sino que incluso pueden llegar a cuestionar los fundamentos de la concepción de justicia en que tales sociedades se reconocen. La justicia, entendida no tanto como compendio de las virtudes que han de caracterizar al sujeto moral, sino como el rasgo distintivo de las instituciones básicas de una sociedad bien ordenada, exige un escenario jurídicopolítico en el que todos los individuos sean iguales ante la ley y estén sometidos a los mismos criterios generales. Tal exigencia de justicia - de la que aquí tan sólo se ha explicitado la igualdad de trato como un criterio mínimo (cf. Dworkin 2003)- también ha de servir de valor-guía a la hora de definir las políticas públicas en general y, en particular, las relacionadas con el fenómeno de la inmigración,
RESUMEN: En este artículo se abordan las reciprocas implicaciones normativas existentes entre las concepciones de la justicia global y de la ciudadanía, por un lado, y la definición de las políticas migratorias, por otro. La exploración se hace en cuatro pasos: se ofrecen algunas razones para superar el enfoque estadocéntrico de la teoría de la justicia; se presentan la pobreza mundial y los flujos migratorios generados por ella como cuestiones ineludibles para una teoria de la justicia; se analizan los obstáculos que las fronteras estatales representan a la hora de implementar una concepción global de la justicia; y, finalmente, se argumenta a favor de redefinir la noción de ciudadanía de modo que constituya el horizonte normativo de las políticas migratorias.

PALABRAS CLAVE: Justicia global; teoria de la justicia; derechos humanos; Rawls; migraciones; políticas migratorias; ciudadanía; fronteras; pobreza mundial; Estado nacional; globalización.

cuya regulación los Estados consideran parte irrenunciable de su domain reservé.

Las diversas políticas que diseñan y ponen en marcha los países de inmigración no se limitan al control del acceso de los extranjeros al territorio nacional o a las condiciones para su estancia legal. Comprenden también a veces un conjunto de medidas destinadas a la consecución de una sociedad integrada en la que tanto nacionales como residentes extranjeros convivan en igualdad de derechos y oportunidades. En virtud de tales políticas, se puede y se debe proceder a una equiparación progresiva de derechos entre todos los residentes, sea cual sea su nacionalidad, así como a una redistribución de los recursos, bienes y servicios hasta entonces disponibles en la que también participen los recién llegados (cf. Zamora 2008). 
Sin embargo, en las sociedades receptoras de inmigrantes, especialmente en las sociedades más ricas, se registran con frecuencia reacciones de resistencia por parte de sectores que, manejando no siempre datos contrastados, sienten amenazado su propio bienestar material. En tales casos, se ha de poner especial empeño en explicar de manera argumentada el sentido de las medidas con el objeto de que los criterios de justicia hasta entonces aceptados no sean revisados a la baja. Si los ciudadanos no están dispuestos a realizar ciertos esfuerzos en pro de una redistribución equitativa de recursos y posiciones de poder, existe el riesgo nada remoto de que emerja una sociedad dual con dos categorías nítidamente diferenciadas de individuos: por un lado, los ciudadanos y, por otro, los migrantes'. Esto implicaría la ruptura del escenario imprescindible para la realización de la justicia, una fractura social inaceptable.

La presencia más o menos permanente de migrantes y refugiados plantea en toda su crudeza la cuestión de los límites de la comunidad política receptora y, en particular, la legitimidad de los límites basados en la nacionalidad de los individuos. La situación real en la que en muchos casos se encuentran los inmigrantes pone de manifiesto que la aplicación de los principios de justicia incluyendo entre tales, y de manera destacada, los derechos humanos sigue aún concibiéndose a partir de una noción restringida de la soberanía estatal como marco de actuación fundamental. De ahi que quienes cruzan las fronteras para instalarse en otro pais experimenten con respecto a los nacionales diferencias relevantes en el nivel de disfrute efectivo de los derechos. La persistencia de este tipo de prácticas resulta sumamente inquietante, pues el respeto de los derechos humanos marca el estándar mínimo de justicia que disfruta en nuestros días de un consenso más amplio, aunque no universal. Al restringirse al ámbito de aplicación de las exigencias propias de la noción de justicia, reduciéndolo al conjunto de los nacionales del país, se está adulterando el potencial universalista inherente a dicha noción. Por eso mismo, la cuestión relativa a la gestión política de los movimientos migratorios $y$, sobre todo, la referente a los derechos que han de tener garantizados los migrantes difícilmente pueden ser esquivadas en un debate serio sobre el sentido de la noción de justicia en el contexto de un mundo globalizado. Sin ocultar la relevancia de este asunto, el reconocimiento de los derechos humanos a todos los individuos en cualquier lugar del planeta no es empero el único tema de la justicia relacionado con la suerte de los migrantes. Esta aproximación al problema adolecería de una cierta estrechez de miras. Existen, por el contrario, relevantes consideraciones que tornan en insuficiente la perspectiva estrictamente estatalista y que invitan a abordar la justicia desde una perspectiva planetaria o, si se prefiere el término, global.

Dado que la opción de salir del propio país en la mayoría de los casos resulta una opción forzada por las circunstan-

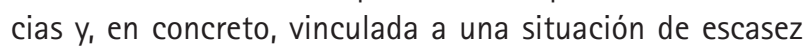
de recursos (en un sentido amplio del término) o de difícil acceso a los mismos a causa de una distribución global no homogénea ni equitativa, existe un estrecho vínculo entre las migraciones y el injusto reparto de la riqueza a nivel mundial. Afrontar las causas de los masivos flujos migratorios internacionales pasa por reconocer que "no vivimos en un mundo justo", una afirmación que, tal como sostiene Thomas Nagel $(2005,113)$, posiblemente sea la "menos controvertida que uno pueda realizar en teoría política". Afirmar lo contrario sería perpetuar en el orden del discurso una imagen falsa de un trágico fenómeno en el que está involucrada la humanidad entera. No es de extrañar, en consecuencia, que entre las cuestiones realmente impostergables de la actual agenda internacional se encuentre la erradicación de la pobreza extrema y el hambre: es, de hecho, el primero de los Objetivos de Desarrollo del Milenio que la ONU definió y aprobó sobre el papel en el año 2000 para su consecución en el 2015.

A lo largo del presente artículo se abordan las implicaciones normativas existentes entre las concepciones de la justicia global y de la ciudadanía, por un lado, y la definición de las políticas migratorias, por otro. El desarrollo de estas cuestiones se efectúa en cuatro pasos: se ofrecen algunas razones para superar el enfoque estadocéntrico de la teoría rawlsiana de la justicia (1); se presentan la pobreza mundial y los flujos migratorios generados por ella como cuestiones ineludibles desde una perspectiva de justicia (2); se analizan los obstáculos que las fronteras estatales representan a la hora de implementar una concepción global de la justicia (3); y, finalmente, se argumenta a favor de redefinir la noción de ciudadanía de modo que constituya el horizonte normativo de las políticas migratorias (4).

Se dejará aquí sin tratar la relevante cuestión relativa a si la vinculación entre migraciones internacionales y pobreza mundial ha de abordarse por métodos distintos a 
los propios de las políticas migratorias, tal como propone, por ejemplo, Thomas Pogge (2010). Esta omisión, sin embargo, no implica negar que, en lugar de intentar lograr la admisión en los países ricos de las personas en situación de pobreza severa, puedan existir otras maneras probablemente mucho más efectivas de proteger a esas personas de las privaciones que están sufriendo. No obstante, es posible argumentar que, precisamente en nombre de la justicia, es preciso replantear las condiciones que habitualmente imponen los paises ricos para la admisión y permanencia de los extranjeros necesitados.

\section{EL PROBLEMÁTICO ÁMBITO DE APLICACIÓN de la teoría de la Justicia}

El tratamiento contemporáneo de la noción de justicia está moldeado en sus rasgos esenciales por la A Theory of Justice de John Rawls, obra publicada en 1971 que delimitó el campo conceptual en donde desde entonces se han librado las principales disputas de filosofía política. Sin embargo, y pese a su pretensión de adecuarse a las sociedades desarrolladas de la modernidad, la doctrina rawlsiana no cuestiona un presupuesto teórico de extraordinaria repercusión práctica: la idea de que los límites de la justicia son los límites de cada uno de los Estados existentes en el planeta (cf. Barry 1989, 20; Singer 2003a, 199). Esta horma intelectual que habitualmente constriñe las aproximaciones al tema de la justicia se encuentra profundamente arraigada en la teoría política contemporánea.

En términos generales, las diversas concepciones contemporáneas de la justicia se configuran como diferentes conjuntos de principios que pueden invocarse para asignar derechos y deberes, así como beneficios y cargas entre los miembros de una determinada sociedad. Pese a las considerables divergencias que pueden apreciarse a la hora de concretar tales principios, las principales teorías rivales coinciden en que un cometido fundamental de la justicia política consiste en afirmar un esquema básico de cooperación social. A esta coincidencia se añade una precisión igualmente compartida: ese esquema básico implica sólo y exclusivamente a todos aquellos que se ubican y comparten un espacio común de actividad. Debido a consideraciones de este tenor, el alcance de las exigencias de justicia se ha restringido tradicionalmente a aquellas sociedades ya constituidas y, en la época moderna, particularmente a los Estados, dentro de los cuales se establecen los términos que regulan la cooperación social. Cada Estado soberano se torna así en unidad idónea para concebir y administrar la concepción de la justicia; por su parte, sus ciudadanos se convierten en sus destinatarios $y$, en el caso de los regímenes democráticos, en los agentes cualificados para discutir sobre ella, pues la justicia concierne precisamente a las relaciones entre conciudadanos. Todo este imaginario político básico se vio reforzado por la hegemonía del marco geopolítico westfaliano, vigente desde mediados del siglo XVII hasta bien entrado el siglo XX. Éste es el marco geográfico $y$, sobre todo, mental en el que se insertan los conceptos de la teoría rawlsiana. De hecho, toda su teoría parte de un presupuesto en nada irrelevante y que, sin embargo, no queda adecuadamente justificado: la idea de que la justicia encuentra su campo de acción más idóneo dentro de sociedades organizadas estatalmente, cada una de ellas tomada como "un sistema cerrado aislado de las demás sociedades" (Rawls 1979, 25). Con ello se da carta de naturaleza al Estado territorial moderno, esto es, a aquella entidad política que ejerce el poder soberano sobre un determinado territorio definido por fronteras reconocidas internacionalmente. Es llamativo que, pese a la relevancia que de este modo se concede a las fronteras, no sea posible encontrar en la obra de Rawls argumento alguno que la acredite ni reflexión alguna sobre las implicaciones morales y políticas resultantes.

Hasta la publicación en 1979 de Political Theory and International Relations, obra de Charles Beitz, el enfoque de la justicia centrado en el Estado (para abreviar, el enfoque estadocéntrico) era el único realmente articulado de manera sistemática. A partir de esa fecha se ha ido erigiendo una corriente de filósofos políticos y teóricos sociales que, si bien se inscriben en la estela de Rawls, se muestran partidarios de aplicar con mayor coherencia su pensamiento político en el ámbito internacional. Además del propio Beitz, entre los integrantes de este grupo liberal-igualitario y cosmopolita se encontrarían, entre otros, Barry, Jones, Pogge, Cole, Nussbaum o Fraser. El auténtico reto al que se enfrentan estribaría en encontrar el modo de sobrepasar el ámbito de las sociedades estatales y desplazar el foco de atención hacia la estructura básica de la sociedad global más o menos integrada, sin perder en el camino ni rigor conceptual ni exigencia normativa (cf. Velasco 2010). Aunque en publicaciones posteriores Rawls intentó

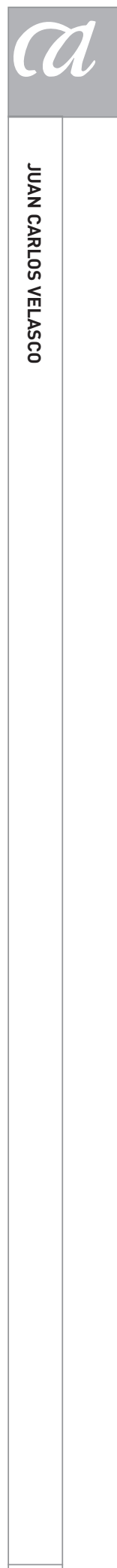


abordar este reto, sobre todo en su escrito El derecho de gentes (Rawls 2001), en realidad se quedó a medio camino, pues, como afirma Singer $(2003 b, 21)$, sigue "firmemente anclado en la idea de que la unidad para decidir qué es justo sigue siendo algo parecido al Estado-nación actual. El modelo de Rawls es el de un orden internacional, no un orden global".

Así, pues, a la apaciguadora postura de Rawls, que se inclinaba por abordar la injusticia y la pobreza en el mundo como una cuestión de mera ayuda humanitaria, le ha salido al paso toda una serie de críticos que apuestan por tratar tales asuntos como cuestiones de estricta justicia distributiva en nombre precisamente de los principios propuestos por Rawls. Estos críticos concuerdan en que no cabe obviar el hecho de que la interrelación entre las distintas sociedades del planeta es hoy más estrecha que nunca y que constantemente las interacciones sociales cruzan las fronteras estatales. La toma en consideración de tales fenómenos de carácter estructural deberia propiciar una reflexión acerca de la necesidad de ampliar las fronteras de la justicia (cf. Nussbaum 2007). De hecho, ante este trasfondo socio-histórico, cuyos perfiles se han acentuado en la era de la globalización (el auténtico presupuesto fáctico de todos estos planteamientos), la determinación del ámbito de aplicación de la justicia, de "quiénes" son sus sujetos, se ha convertido en materia expresa de un debate académico a tres bandas entre nacionalistas liberales, internacionalistas y cosmopolitas (cf. Fraser 2008, 67-79). En el transcurso de esas disputas, la postura de Rawls, identificada básicamente con el primer grupo, ha pasado a ser una más entre los diversos esfuerzos para pensar la justicia social en un mundo globalizado. Los nacionalistas liberales estiman que las exigencias de la justicia son de aplicación exclusivamente en el interior de los Estados nacionales y, por tanto, no contemplan ninguna provisión de justicia de alcance inter- o transnacional, una posición que es impugnada conjunta y vehementemente por los otros dos grupos. Pero mientras que los cosmopolitas o globalistas consideran que el objeto de la justicia son las relaciones entre todos los seres humanos y que, por tanto, la unidad básica de distribución son las estructuras globales, los internacionalistas presuponen una estructura básica de doble nivel (nacional e internacional) con grados distintos de obligaciones distributivas. Así, pues, internacionalistas y globalistas sostienen, con los matices apuntados, que desde una posición liberal atenta a una distribución equitativa de derechos y recursos, esto es, desde una perspectiva rawlsiana que no se mantenga en la literalidad de Rawls pero que consume el sentido de su teoría, los principios de la justicia habrian de tener una aplicación global o internacional de modo que los recursos disponibles sean tratados y gestionados en una escala mundial. Aunque, en concreto, autores como Beitz, Nussbaum o Fraser ni lo contemplan (tan sólo, de alguna manera, Cole 2000 y Pogge 2010), la citada estrategia argumentativa permitiría, como se verá más adelante, que asuntos como, por ejemplo, los relativos a los flujos migratorios fueran considerados desde una perspectiva mucho más integral.

En puridad, y para ser justos también con Rawls, cabe distinguir dos propuestas a lo largo de su obra, cuya diferenciación tiene consecuencias significativas en los debates a tres bandas recién mencionados: por un lado, una primera teoria en la que se trazan con bastante detalle los rasgos de una sociedad justa (Rawls 1979); y, por otro, una concepción, mucho menos articulada, acerca de las relaciones justas entre los pueblos (Rawls 2001). Una de las principales disparidades que se perciben entre estas dos propuestas es que mientras la primera va encaminada a lograr un acuerdo sobre los criterios públicos para la valoración, el

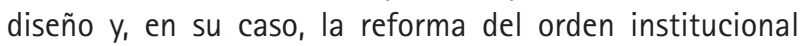
de una sociedad (su "estructura básica"), la segunda tan sólo aspira a obtener un conjunto de normas de buena conducta que los pueblos en cooperación tendrian que seguir. Cabe entonces hablar, como bien ha señalado Pogge (2004), de una "asimetría estructural" entre ambas teorías rawlsianas. Y ello es así a pesar de que "el derecho de gentes se desarrolla dentro del liberalismo político y constituye una extensión de una concepción liberal de la justicia doméstica a una sociedad de los pueblos" (Rawls 2001, 19). En todo caso, los niveles de exigencia normativa aplicables en uno $u$ otro ámbito difieren ostensiblemente.

Existe otra notable asimetria entre ambas concepciones que empaña la credibilidad de la teoría internacional propuesta por Rawls: en el ámbito interno de los Estados este autor adopta un individualismo normativo que rechaza de plano en el ámbito supra- o interestatal. Por tal forma de individualismo se entiende aquella "concepción que, respecto al establecimiento de las cuestiones morales, asume que sólo deben contar los intereses de los seres humanos individuales" (Pogge 2004, 32). Pues bien, mientras que en su teoría intraestatal, restringida al ámbito interno o local (domes- 
tic), los intereses colectivos alcanzan un peso inapreciable, en su teoría internacional "los pueblos son reconocidos como las últimas unidades de interés" (Pogge 2004, 32). Y aqui por pueblos se entiende las entidades jurídico-políticas reconocidas a nivel internacional, es decir, los Estados. Una compresión que, por un lado, guarda suma coherencia con un presupuesto básico del modelo westfaliano -los sujetos del derecho internacional son exclusivamente los Estados (cf. Zolo 2000, 137-140)- y que, por otro, choca frontalmente con el contenido potencialmente cosmopolita de los derechos humanos que apunta hacia el reconocimiento de los individuos como sujetos del derecho internacional. Si desde una genuina perspectiva cosmopolita, la primera preocupación debería ser, según Rawls $(2001,138)$, "el bienestar de los individuos y no la justicia de las sociedades", en su obra El derecho de gentes lo relevante pasa a ser la estabilidad del sistema de Estados y no la redistribución de recursos entre todos los habitantes del planeta, cuestión que sitúa expresamente fuera del objeto de la teoría. De ahí que tanto internacionalistas como globalistas se posicionen en contra de Rawls y postulen un sentido ampliado de justicia que sobrepase el terreno acotado de cada sociedad cerrada en sus propias fronteras.

No existen razones suficientes para afirmar que los efectos injustificados de la desigualdad en el orden social internacional tengan que ser tratados de manera diametralmente diferente a los problemas de justicia en la esfera interna. Sin embargo, en El derecho de gentes, Rawls tan sólo contempla formalmente un mero deber de asistencia internacional, siendo además el último que enumera entre los principios de justicia entre pueblos libres y democráticos: "Los pueblos tienen el deber de asistir a otros pueblos que viven bajo condiciones desfavorables que les impiden tener un régimen político justo o decente" (Rawls 2001, 50). Se entiende que este deber es de aplicación en aquellos casos en que la pobreza amenaza el buen ordenamiento interno de una determinada sociedad. De este deber no se deduce, sin embargo, la exigencia de ningún arreglo institucional de alcance internacional $y$, en definitiva, queda sujeto a la libre negociación entre los Estados soberanos. Es precisamente esta falta de ambición lo que conduciría al planteamiento rawlsiano a la más completa irrelevancia en un mundo que demanda patrones normativos globales.

Entre las razones que mueven a Rawls a no extender el mencionado individualismo normativo a la esfera interna- cional destacan dos argumentos de muy distinto tenor. El primero se basa en la convicción, aunque presentada como si fuera un hecho incontrovertible comprobado por las ciencias sociales, de que las causas de la pobreza nacional y de la desigualdad internacional obedecen a circunstancias de carácter puramente interno, incurriendo así en un claro alarde de nacionalismo explicativo. Se trata de una afirmación difícilmente sostenible si se tienen en cuenta los datos empíricos disponibles y, sobre todo, el alto grado de interconexión e interdependencia alcanzado por la economía mundial ${ }^{2}$. El segundo argumento descansa en la negativa a diseñar un orden institucional global. Rawls descarta esta posibilidad amparándose sencillamente en un argumento de autoridad: "Sigo aquí a Kant en La paz perpetua en que a un gobierno mundial que entiendo como un régimen político unificado con los poderes legales ejercidos habitualmente por los gobiernos nacionales sería un despotismo global o un frágil imperio desgarrado por frecuentes guerras civiles" (Rawls 2001, 49). Pero aún aceptando esta objeción, no está nada claro por qué Rawls se niega a estudiar otras posibilidades, entre las que destacarian las siguientes: una libre federación de Estados soberanos (que era la segunda opción manejada por el propio Kant), alguna federación con atribuciones de coordinación o incluso algún tipo de organización supranacional de carácter continental (como la Unión Europea). Y, sobre todo, tampoco se explica por qué Rawls sigue otorgando prioridad al marco estatal como ámbito óptimo exclusivo, en la práctica para la resolución de los problemas de justicia distributiva. Estos argumentos serán abordados y rebatidos en los dos siguientes apartados.

\section{Pobreza mundial y MigRaciones INTERNACIONALES}

Entre los pasajes más controvertidos de El derecho de gentes de Rawls se encuentra aquél en el que se afirma que la carencia de un mínimo de bienestar en ciertas sociedades no obedece fundamentalmente a la escasez de recursos naturales, ni tampoco a la existencia de condiciones no equitativas de intercambio y de dominación política, sino a las tradiciones culturales y hábitos políticos (gobiernos opresivos y élites corruptas, en particular) de algunos pueblos, asi como por la falta de laboriosidad, probidad y capacidad de sus miembros (cf. Rawls 2001, 125-126). Las

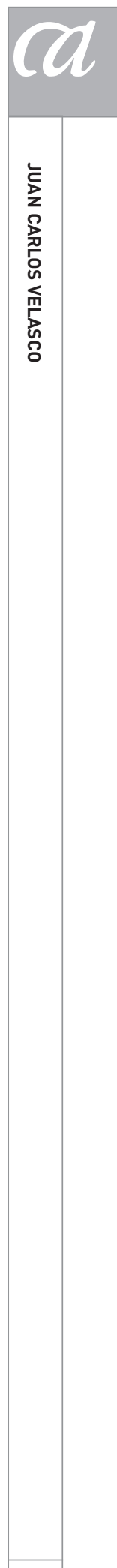

ARBOR CLXXXVI 744 julio-agosto [2010] 585-601 ISSN: 0210-1963 
causas de la pobreza serían, por tanto, estrictamente endógenas a cada país. Del mismo modo procede con la cuestión migratoria, reduciendo las diferentes causas de los flujos a una principal: la ausencia de instituciones y estructuras liberal-democráticas estables en los paises emisores (cf. Rawls 2001, 18; 51-52). Si tal explicación se concibe en estrechos términos político-institucionales, resulta difícil darla por válida ${ }^{3}$. Si, por el contrario, se interpreta en el sentido de que en el origen de las migraciones se encuentra la ausencia de una estructura social bien ordenada, esto es, el carácter injusto de las relaciones sociales, se apuntaría entonces en una dirección correcta. Pero aún aceptando esta interpretación, resulta enormemente difícil emitir un juicio sobre la estructura social remitiéndose en exclusiva al ámbito estatal y olvidándose de la incardinación de los Estados en una estructura de intercambio mucho más amplia de carácter planetario.

El enfoque puramente estadocéntrico de la justicia, que concibe a los Estados como si fueran mónadas leibnizianas autosuficientes que no interactúan entre sí, podría estar justificado acaso en tiempos pretéritos. En otros momentos de la historia existían dificultades prácticamente insalvables para establecer contactos y relaciones permanentes con lugares alejados, pero hoy tales motivos no pueden invocarse más (cf. Barry 1995, 21). Las capacidades de beneficiar o perjudicar se han globalizado y no sólo en las relaciones interpersonales, pues "las posibilidades de beneficios y males se multiplican más allá de toda medida cuando se trata de las políticas que los gobiernos ponen en práctica en nuestro nombre" (Appiah 2007, 15). Por eso mismo, "cada país", como señalaba Hannah Arendt $(2001,91)$ ya a mediados de la centuria pasada, "se ha convertido en el vecino casi inmediato de cualquier otro pais, y cualquier persona siente el golpe de los hechos que suceden en el otro extremo del globo". En este punto, como en tantas otras cuestiones, desde el inicio de la modernidad las condiciones materiales de existencia han cambiado de tal manera que se ha modificado de manera no banal aquello que, desde David Hume (1993 [1751], 4752), se conoce como las circunstancias de la justicia, esto es, aquellas condiciones socio-históricas bajo las cuales se hace necesaria la cooperación humana.

A escala planetaria, las circunstancias son ahora tan extremas o más que en cualquier otro momento del pasado, pues en los últimos dos siglos los procesos de desarro-
Ilo desigual han provocado entre los paises disparidades económicas sin parangón (al menos desde que se tiene registro fehaciente). Si se acepta que, en lo relativo al problema de la distribución de la riqueza, existe una analogía fundamental entre las sociedades estatales y la sociedad global (cf. Dower 1995, 379) y que, además, las obligaciones que cada cual tiene ante sus conciudadanos no son esencialmente diferentes que las que tiene ante los demás miembros de la humanidad, entonces ha de concluirse que hay razones suficientes para impulsar acuerdos a favor de una auténtica redistribución internacional de la riqueza conforme a un tratamiento equitativo global (cf. Beitz 1979; Pogge 2005).

Una teoría normativa de la justicia no puede ignorar que el abismo que se abre entre los Estados más ricos y los más pobres del planeta es ahora más profundo que nunca. Tampoco debería hacerlo una teoría que pretenda dar una explicación convincente de las migraciones internacionales contemporáneas. Los actuales procesos de globalización se caracterizan, entre otras cosas, por su profunda asimetría $y_{1}$ en particular, por la desigualdad económica que generan entre las diferentes regiones del planeta ${ }^{4}$, desigualdad que se multiplica por el hecho de que "la globalización supone la intersección de múltiples estructuras de injusticia" (Fraser 2008, 89), entre las que se situarían en un lugar destacado las derivadas de la pervivencia de relaciones post- y neocoloniales (realidades que la teoría liberal de la justicia tiende a ignorar, cf. Cole 2000). La persistencia de situaciones de injusticia enquistadas se encuentra detrás aunque no como factor único ni como exclusivo desencadenante del continuo incremento de los movimientos migratorios a escala mundial registrado en los últimos años, así como del que previsiblemente tendrá lugar, pues "en la medida en que la globalización signifique la inclusión de ciertas áreas en la prosperidad económica global y la exclusión de otras, la inmigración seguirá creciendo" (Castles 2004, 53). En un planeta cuya superficie seguirá teniendo la misma extensión y cuyos territorios habitables disminuyen desde hace tiempo por causa de la desertificación (entre otros factores), el aumento igualmente predecible de la población mundial en las próximas décadas más acentuado además en las regiones menos desarrolladas del planeta empujará, sin duda, en la misma dirección.

Aunque existen flujos de personas originados por situaciones de emergencia coyuntural (guerras civiles, catástrofes 
naturales, etc.), la mayor parte de las migraciones tienen una dirección definida que va desde las áreas más pobres hacia las zonas ricas y que, en gran medida, son resultado de una situación estructural injusta, de una distribución no equitativa de la riqueza, de los recursos naturales y del llamado capital humano. Por eso, si se busca comprender las migraciones de manera integral, esto es, como un proceso de escala global, no puede perderse de vista las relaciones norte-sur en el sentido no de referencias geográficas, sino de configuraciones político-sociales que cristalizan en formidables disparidades "en materia de prosperidad económica, condiciones sociales, seguridad y derechos humanos" (Castles 2004, 54) ${ }^{5}$.

En la mayoría de los casos, hablar de las migraciones como un éxodo voluntario constituye una representación completamente falaz de la realidad, pues los márgenes de acción y de decisión individual son enormemente restringidos en situaciones de escasez y penuria económica. No obstante, hay que tener en cuenta que, aunque detrás de muchos procesos migratorios en cuanto fenómeno social y no como resultado de decisiones individuales estén la pobreza y la búsqueda de mejores oportunidades de vida, la identificación del factor desencadenante de las mismas (que no hay confundir con su causa última) resulta sumamente compleja. En la práctica general, es preciso que confluyan otras circunstancias para que la pobreza opere como factor de estímulo de la emigración. La existencia de antiguos vínculos coloniales $y$, sobre todo, de redes migratorias transnacionales son, por ejemplo, factores que facilitan el inicio del proceso migratorio. De especial relevancia son los efectos provocados por interacciones constantes de todo tipo entre los distintos países, cuya multiplicación ha sido propiciada por las últimas olas de globalización. Y ello implica aseverar que las migraciones en parte también están determinadas por los países receptores (cf. Sassen 2006), aunque no en exclusiva, pues además de poderosas razones que inciten a las personas a salir de su propio país (push factors), tiene que haber motivos que impulsen a instalarse en determinados países (pull factors). Con todo, los polos de atracción sólo suelen llegar a ser tomados en consideración después de que en los países emisores se hayan manifestado al menos algunas de las siguientes circunstancias desfavorables: una desigualdad social profunda y enquistada, un crecimiento demográfico descontrolado y/o una alarmante desestructuración económica, social y cultural.
Si la pobreza mundial constituye, en su mayor parte, una vulneración de los derechos humanos (cf. Pogge 2005) $y$, en particular, una flagrante violación del art. 25 de la Declaración Universal de Derechos Humanos (DUDH) que establece el derecho a un nivel de vida adecuado, entonces las migraciones motivadas por razones económicas serían, en última instancia, resultado de un quebrantamiento masivo de los derechos humanos. Además, si resulta correcto comprender los derechos humanos como el mínimo básico debido a todos los seres humanos, de ahí se desprende que el ideal de justicia está íntimamente vinculado con la noción de derechos humanos, cuya garantía constituiría entonces un deber de justicia. Una de la primeras implicaciones de la noción de justicia es la exigencia de poner punto final a las situaciones de injusticia activa, así como la de compensar a los perjudicados por el mal que se les haya hecho. La injusticia que subyace a tantos desplazamientos migratorios tampoco debería quedar sin compensación. Entre las compensaciones de justicia imaginables se encontraría, por ejemplo, la siguiente: "mientras persista el inmenso contraste entre naciones ricas y pobres, la justicia, que exige que las ricas lo corrijan tan rápida y completamente como les sea posible, también exige que éstas no alcen o refuercen sus barreras contra la entrada de gente procedente de los países pobres" (Dümmett 2004, 82). En un sentido similar se manifiesta el Informe sobre Desarrollo Humano 2009, que lleva por título Superando barreras: movilidad y desarrollo humano (cf. PNUD, 2009), en el que se argumenta de manera convincente a favor de que facilitar la movilidad humana favorece de manera decisiva el desarrollo humano entendido como aumento integral de las capacidades de todas las personas que habitan el planeta ${ }^{6}$.

La teoría de la justicia más emblemática de los últimos tiempos, la elaborada por Rawls, no está especialmente dotada, como ya se ha indicado, para afrontar la cuestión migratoria desde una perspectiva global. La razón de esta carencia estriba en uno de sus supuestos básicos: su objeto no es otro que el de regular la relación entre cada Estado y sus propios ciudadanos, por lo que, ya de entrada, los inmigrantes no cuentan como actores que participan en los acuerdos sobre la justicia (cf. Cole 2000). Esta exclusión inicial implica una vulneración del principio de igualdad, pues las cargas y los beneficios sociales no se atribuyen de igual manera a todas las personas residentes de facto en el territorio estatal. Procediendo de esta manera, el

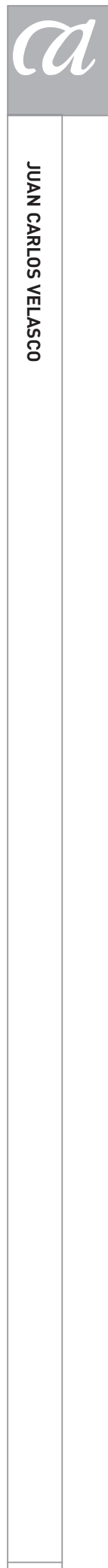

591 
acceso de los inmigrantes a las prestaciones sociales -no homogéneo además, pues con frecuencia está diferenciado conforme a las posiciones jurídicas estratificadas que ocupan los diversos tipos de residentes (cf. Morris 2002)- se presenta en las sociedades receptoras como una fuente de conflictos que tarde o temprano acaban por aflorar. El problema se agrava por la perspectiva estadocéntrica adoptada y es precisamente este error de enfoque el que tanto globalistas como internacionalistas pretenden rectificar. Tales teóricos, aunque sin llegar aún a presentar una solución coherente al desafío de la participación plena de los inmigrantes en la sociedad receptora, se encuentran mejor predispuestos a aceptar que las migraciones son un fenómeno de dimensiones planetarias que ningún Estado puede orientar ni canalizar eficazmente, pues sus causas se encuentran tanto en los paises emisores como en los receptores, de modo que no tiene sentido tratarlas como si fueran una cuestión de mera política interior. Ningún país dispondria de los medios precisos para controlar todas las variables en juego. Por tanto, la visión estatal no puede ser enarbolada como marco único de actuación política y menos aún en esta materia.

\section{Fronteras estatales, Justicia e instituciones GLOBALES}

Ante la conversión del fenómeno migratorio en producto masivo, la exigencia de superar la concepción tradicional de las fronteras nacionales emblema de la soberanía estatal se torna perentoria. La intensidad alcanzada por dicho fenómeno hace saltar por los aires el escenario jurídico-político habitual de realización tanto de la justicia social como de la democracia: los Estados nacionales. En la práctica, los principios de la justicia tienen unos límites materiales muy precisos: las fronteras. En ellas se hace concreto el primado de la lógica estatal, una lógica incompatible con las exigencias universalistas de la justicia. Sin embargo, resulta difícil de aceptar sin más que un asunto tan azaroso como el trazado de las fronteras producto de contingencias históricas, luchas territoriales, choques culturales o actos burocráticos haya de tomarse como una circunstancia moralmente relevante a la hora de definir y aplicar principios de justicia. Nadie elige el lugar de su nacimiento y, por tanto, nadie puede responder por ello. Sin embargo, una frontera levantada con criterios administrativos hace que, según el lado en que se haya nacido, uno disfrute ya de entrada de infinidad de oportunidades materiales o carezca de lo más mínimo para llevar una vida digna, uno tenga reconocidos derechos y libertades básicos o se encuentre privado de cualquier protección jurídica. En ocasiones, en virtud de la interposición de fronteras, se dejan en suspenso incluso alguna de las obligaciones más básicas en las relaciones interpersonales, como podría ser el deber de auxilio. A este respecto, Rawls se muestra muy humano, quizás demasiado humano, pues al dar por bueno el clásico esquema westfaliano basado en el Estado territorial soberano está admitiendo que "el sentido de la justicia se refracta al traspasar las fronteras, como la luz al cambiar de medio" (Álvarez 2007, 154). Y lo peor no es ciertamente que esta posición encuentre reflejo en las construcciones teóricas más reputadas ${ }^{7}$, sino que represente el motivo central de tantas prácticas políticas. Como cabe observar con harta frecuencia, los principios de justicia se olvidan cuando se traspasan las fronteras y sobre ellos adquieren primacía los intereses nacionales particulares.

Para modificar el panorama arriba enunciado se necesitan nuevas estructuras político-conceptuales con las que poder desarrollar un modelo de convivencia en el que "los accidentes de nacimiento y origen nacional no viciaran desde el principio y en todos los sentidos las opciones vitales de las personas" (Nussbaum 2007, 22). No cabe determinar si una sociedad es justa sin evaluar los criterios por los que se regula la pertenencia a ella, así como los criterios que permiten el acceso, la movilidad y la permanencia de las personas en su territorio. Por ello, tanto los criterios para la adquisición de la ciudadanía (que se examinarán en el siguiente apartado) como los criterios de fijación de las fronteras y de sus consecuencias normativas constituyen cuestiones ineludibles para una teoria de la justicia. Así, siguiendo el mismo esquema conceptual de Rawls, aunque no su letra (o, como dirian los alemanes, mit Rawls gegen Rawls denken), bien podría pensarse que, sin saber dónde han de nacer, las distintas partes presentes en la posición original -aquel experimento mental que vertebra por entero la teoría rawlsiana de la justicia- querrán asegurarse que ningún sistema de fronteras territoriales legitimará disparidades sustantivas que impidan el acceso a recursos y oportunidades necesarias para llevar una vida digna y reconocerán la libertad de movimientos como un derecho universal (cf. Carens 1987). Y si, pese a todo, en ese acuerdo inicial se diese por bueno un mundo organi- 
zado mediante fronteras, las distintas partes estipularían, al menos, que los países ricos que se negaran a compartir su riqueza perderian la potestad de vedar la entrada en sus territorios (cf. Kymlicka 2006).

Si se acepta que todos los seres humanos tenemos el deber de ayudar a nuestros congéneres que se encuentran en un estado de necesidad extrema, no resulta muy defendible argüir que tal deber decae completamente con respecto a quienes se encuentran más allá de las fronteras del territorio estatal en el que uno vive. En este caso, haríamos nuestra una dudosa noción de responsabilidad moral. Violaríamos además el principio de no discriminación, de igual consideración de todos los seres humanos. Esto no implica, sin embargo, negar que existan deberes especiales con respecto a aquéllos con quienes se ha establecido un sistema reconocido de cooperación y responsabilidades mutuas (cf. Singer 2003a, 183). Pero con todo, y pese a la legitimidad de esta vía de argumentación, al adentrarnos en ella es fácil incurrir en discusiones sobre la naturaleza de la obligación moral que en el fondo no son decidibles racionalmente. Por ello resulta preferible incidir dialécticamente en las consecuencias pragmáticas que, a escala global, tiene el obrar de manera no solidaria.

Aunque difícilmente se llegue a un consenso sobre ellas, tiene sentido plantearse cuestiones del siguiente tenor: ¿existe un deber de asistencia, basado en la apelación a la justicia, más allá de los límites de la comunidad de la que formamos parte y con la que nos encontramos ligados por vínculos de cooperación mutua y reciprocidad? 0, por el contrario, ¿no están vinculados todos los deberes a un contexto de interacción social determinado? Es posible que muchas personas coincidan en juzgar como algo arbitrario limitar el ámbito espacial de aplicación de las normas morales, de los deberes y obligaciones. Pero también serian muchos quienes discrepasen a la hora de considerar irrelevante el hecho de que los destinatarios de nuestras labores de asistencia pertenezcan a nuestra propia comunidad. Si bien es un hecho constatable que esta última opinión está enormemente extendida, quizás obedezca a una falta de información acerca de cuál sea el ámbito real de interacción. Si esto es así, parece más pragmático argüir de manera consecuencialista, pues limitar nuestra comunidad de pertenencia a determinadas fronteras políticas implica desconocer que la humanidad entera comparte de facto un mismo mundo, que todos estamos continuamente interactuando y estableciendo transacciones.

Más allá de los imperativos ineludibles de una economía globalizada, en las últimas décadas se han ido haciendo presentes toda una serie de cuestiones y desafíos cuya etiología y resolución trascienden los límites estatales. No se trata de una mera suma de cuestiones puntuales, aunque destacadas, sino algo mucho más serio y relevante: que la especie humana en su conjunto constituye una comunidad que, quiera o no, comparte un riesgo global (cf. Beck 1998). Esa serie de riesgos compartidos (cambio climático, pandemias, flutuaciones de los mercados financieros, etc.) por toda la comunidad de los humanos plantea la cuestión del papel que al Estado-nación le cabe desempeñar frente a unos problemas que no se detienen ante las fronteras espaciales entre Estados ni tampoco ante las fronteras temporales entre generaciones. En este contexto, las fronteras estatales o bien se han vuelto enormemente porosas o bien han perdido gran parte de su relevancia y funcionalidad. De ahí que no se pueda seguir negando por más tiempo la capitidisminuida proyección del Estado, su progresiva obsolescencia como forma básica y ordinaria de organización política. Cabe hablar, siguiendo a Bauman (2001, 11), de "los efectos inhabilitantes de la globalización sobre la capacidad decisoria de los gobiernos estatales". De hecho, cada día resulta más patente la brecha entre el ámbito decisorio institucional y el universo en el que se producen y distribuyen los recursos necesarios para la toma y ejecución de las decisiones. Es evidente que, "en un mundo cada vez más densamente entretejido ecológica, económica y culturalmente, las decisiones que, en virtud de su competencia legítima, pueden adoptar los Estados en su ámbito territorial y social coinciden cada vez menos con las personas y territorios que pueden ser afectados por ellas" (Habermas 2000, 95). Pero las limitaciones no afectan únicamente al plano de la eficacia, sino también al de los principios y fines de la política. En este sentido, la lógica propia del Estado como forma de organización política no resulta ni propicia ni sensible a una visión multilateral de las relaciones internacionales.

Aún está por resolver en clave democrática la cuestión relativa a las consecuencias derivadas de la creciente interdependencia de todos los pueblos, pero cuestiones tan cruciales como el respeto de los derechos humanos, el equilibrio ecológico del planeta o la gestión democrática 
de los flujos migratorios mundiales precisan de un cambio en profundidad de los principios estructurales del orden mundial $y$, en particular, del derecho internacional en lo referente, al menos, a la no intervención en asuntos de la jurisdicción interna, la igualdad soberana de todos los Estados o la cooperación entre ellos. Al establecimiento de un orden mundial diferente haria referencia precisamente el art. 28 de la DUDH: "Toda persona tiene derecho a que se establezca un orden social e internacional en el que los derechos y libertades proclamados en esta Declaración se hagan plenamente efectivos". De este artículo se deduce que una de las funciones básicas del concepto de derechos humanos es la de servir como criterio para conformar las instituciones no sólo nacionales sino también internacionales. Es cierto que ni los entramados jurídicos e institucionales ni la legitimidad moral garantizan por sí mismos la resolución de los conflictos, pero sin ellos parece difícil que pueda ni siquiera plantearse una respuesta eficaz. En un marco global, en donde se hacen presentes cada vez con más fuerza problemas sistémicos de alcance planetario, se requiere que todos los Estados pongan en común recursos, tecnología, servicios de información y también su autoridad, esto es, se precisa una respuesta necesariamente multilateral y coordinada, que haga también posible "reestructurar radicalmente el sistema económico mundial" de acuerdo con las obligaciones de justicia (Beitz $1979,127)$. Una redistribución que no puede quedarse en cambios cosméticos ni en apelaciones retóricas, sino que debe afectar al nivel estructural.

Los problemas globales más graves ya no pueden ser resueltos adecuadamente en el estrecho marco de actuación de los Estados nacionales y se hace patente la necesidad de algún tipo de integración política de carácter supranacional. De hecho, el surgimiento de entidades supranacionales de carácter regional o continental responde a esa contrastada necesidad de actuar concertadamente. En este sentido, el camino emprendido por la Unión Europea constituye una experiencia muy valiosa y su ejemplo podría dar pie a otras formas de integración más amplias a lo largo del planeta. Con todo, hasta lograr la articulación de una instancia realmente mundial aún falta mucho trecho y la propia propuesta plantea toda una larga serie de interrogantes difíciles de resolver. Junto al establecimiento de un poder judicial con jurisdicción a escala mundial encargado de velar por los derechos humanos, ¿sería necesario también un poder legislativo permanente, así como un poder ejecutivo que tuviera encomendada la misión de poner los medios coactivos necesarios para hacer cumplir las sentencias del poder judicial? De un modo más concreto, ¿resulta suficiente la instauración ya lograda del Tribunal Penal Internacional para garantizar con eficacia la cobertura internacional de los derechos humanos? ¿0, más bien, sería preciso instaurar un Estado mundial en sentido estricto? Obviamente, dar respuesta cabal a estas cuestiones requeriría un marco teórico mucho más amplio y fundamentado del que aquí cabe presentar ${ }^{8}$.

Volviendo al ámbito concreto del que se ocupa este artículo, el fracaso casi permanente de las políticas migratorias desarrolladas por distintos Estados se ve agravado, sin duda, "por la ausencia relativa de un gobierno global con respecto a la migración internacional, en contraste con el desarrollo de reglas e instituciones globales en otras áreas de relaciones económicas y políticas" (Castles 2006, 52). Sorprende que en un mundo empeñado en eliminar todos los posibles impedimentos a los movimientos de capitales, bienes y servicios, no haya ningún organismo internacional que tenga como misión propia levantar las restricciones a la movilidad internacional de personas. La aproximación al fenómeno migratorio siempre resultará unilateral e incompleta si se realiza desde una lógica nacional estrecha. En la medida en que "la globalización está introduciendo una cuña cada vez más ancha entre la territorialidad estatal y la efectividad social" (Fraser 2008, 56), los márgenes soberanos de actuación de cada Estado se ven limitados en el ámbito global. De este modo, también en esta materia se hace valer la idea de que no existen soluciones locales para problemas globales. Para salvar este importante escollo sería preciso establecer un régimen migratorio global con un sólido soporte normativo.

Los migrantes económicos, que sin duda constituyen la inmensa mayoria de las personas migrantes, carecen de efectivos instrumentos de derecho internacional que los amparen expresamente. Y si disponer de unas reglas generales reconocidas por toda la comunidad internacional es un prerrequisito para el establecimiento de un régimen jurídico global, para su implementación y supervisión se requeriria además una agencia específica con autoridad efectiva sobre los paises donde se asienta el grueso de la migración internacional ${ }^{9}$. Es cierto que desde 1951 existe la Organización Mundial para las Migraciones, pero se trata de una organización intergubernamental fuera del 
sistema de las Naciones Unidas que carece, aunque sea la principal agencia mundial en esta materia, de un mandato jurídico de protección de los migrantes. Como muchas otras instituciones internacionales, no posee verdadera capacidad reguladora y se limita a emitir informes y marcar pautas de alcance estrictamente retórico. Su experiencia acumulada podría servir, no obstante, como base para establecer una agencia con mayor nivel de responsabilidades, categoría jurídica y capacidad ejecutiva, que a su vez diera soporte institucional a un acuerdo de eficacia global sobre las migraciones internacionales. La nueva agencia debería evitar incurrir en las mismas patologías de las que adolecen otras agencias internacionales. Como es bien sabido, una creciente red de organizaciones internacionales tratan de atender a las crecientes necesidades de coordinación y regulación en una sociedad mundial altamente interdependiente. Sin embargo, estas instituciones "no cumplen las condiciones de la transparencia, la accesibilidad y la responsabilidad" (Habermas 2009, 181). La democratización de la esfera internacional es una asignatura pendiente, cuya superación también tendría que llegar a esa futura organización dedicada específicamente a regular y supervisar los derechos de los migrantes.

\section{Migraciones y resignificación de la ciudadanía}

La división política del planeta sirve con frecuencia como coartada a distribuciones injustas de los recursos y oportunidades básicas que cada individuo en particular padece o disfruta según disponga la fortuna. De entrada, la mera posesión de un status de ciudadanía concreto, como expresión de la pertenencia formal a un Estado determinado, prefigura unas oportunidades diferenciadas en el acceso de los recursos mundiales. El hecho mismo de la división en Estados conlleva la atribución a los individuos de condiciones jurídicas diferenciadas, condiciones igualmente asociadas a la ciudadanía, una institución cuya relevancia, centralidad y actualidad son bien conocidas (cf. Kymlicka y Norman 1997). Sin embargo, no puede obviarse que la posesión de un determinado status de ciudadanía es, como sucede también con la delimitación de las fronteras estatales, una contingencia arbitraria en términos morales que puede llegar a influir dramáticamente en las condiciones de vida de las personas, en los derechos reconocidos y en los bienes públicos a los que tienen acceso. Estas posibles repercusiones se hacen especialmente visibles en los contextos migratorios. De ahí que la dicotomía nacional/extranjero, habitual en los ordenamientos jurídicos, resulte cuestionable tanto a la luz del valor de la dignidad humana como de los principios generales de igualdad de trato y de interdicción de la discriminación ${ }^{10}$. Tampoco en este punto las exigencias igualitaristas y de universalización de los derechos humanos deberían ser echadas en saco roto.

El contexto contemporáneo en el que se ha de pensar la ciudadanía como materia propia de la noción de justicia está conformado por la globalización, esto es, por el conjunto de cambios estructurales que han ido haciendo que los límites del espacio de intercambio humano coincidan de una manera real y no sólo posible con los límites, cambios que a su vez generan un sensible incremento de los niveles de interdependencia entre las diversas partes del planeta (cf. Giddens 2007, 69 y ss). Pero no sólo como resultado de la globalización económica y, en especial, de la deslocalización de los capitales, sino también por efecto de las peculiaridades de los flujos migratorios contemporáneos, lo político está sometido al influjo creciente de lo transnacional, que incide directamente sobre la estructura y funciones del Estado, así como sobre el contenido y el significado de la ciudadanía. En la nueva espacialidad de un mundo enormemente ensanchado, la constitución y consolidación de redes migratorias transnacionales, que se extienden sin pararse ante las fronteras territoriales por muy fortificadas que estén, ponen a prueba las concepciones habituales acerca de los fundamentos de derechos y obligaciones individuales y ponen asimismo en evidencia la necesidad de reformular el ámbito territorial de las nociones clásicas de la ciudadanía (cf. Velasco 2009).

El estrecho vínculo que la institución de la ciudadanía mantiene tradicionalmente con el Estado-nación le confiere un matiz discriminador y excluyente: en el caso de la anhelada ciudadanía de los países más desarrollados, es un bien escaso del que inmigrantes y asilados se ven privados en un mundo asimétricamente globalizado. Lejos de presentarse como un principio universalista, la ciudadanía usualmente funciona como cláusula de cierre de la comunidad política. Cierto es, no obstante, que mediante la articulación de los procedimientos de naturalización, también puede fungir como cláusula de apertura de la comunidad política. Por ello, y pese a que las políticas migratorias se reducen, en general, a la puesta en marcha de

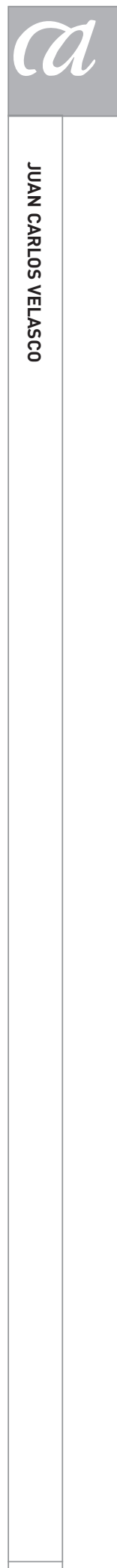

595 
mecanismos de control, que tienden a organizar, dominar y ordenar los flujos migratorios y su densidad, entre las medidas políticas que un Estado ha de tomar en relación con el fenómeno migratorio nunca debería faltar la regulación de la adquisición de la ciudadanía, pues representa un instrumento fundamental para visualizar el horizonte final de expectativas que se le ofrece a cada migrante en su proceso de inserción dentro de la sociedad receptora.

En la práctica, el que un migrante ostente una determinada nacionalidad prefigura su situación jurídico-política en el país en el que se haya asentado. No es lo mismo de qué país se sea nacional. También las posibilidades reales de movimiento, en particular, las posibilidades de emigrar a otro Estado, se derivan de la nacionalidad/ciudadanía que uno posea. Estos posibles efectos plantean, no obstante, dos cuestiones distintas, al menos desde una perspectiva analítica, que además admiten un tratamiento normativo diferenciado: una hace referencia a las condiciones de entrada de los inmigrantes y otra a las condiciones de permanencia, es decir, al trato jurídico que reciben los que ya están instalados en el país. Puede aducirse, dado el caso, motivos pragmáticos y coyunturales para justificar restricciones en la entrada de inmigrantes (aunque muy difíciles de argumentar si tan sólo incumben a los procedentes de ciertos países) que, sin embargo, no justifiquen la limitación de los derechos de estancia de los ya instalados. Las condiciones de entrada que imponen los distintos Estados y que afectan directamente al derecho a la movilidad, al libre movimiento de las personas, están con frecuencia alejadas de una concepción moral universalista (cf. Carens 1987).

La alta tasa de movilidad, una de las señas distintivas de los tiempos que corren, tiende a distribuirse de manera piramidal y asimétrica entre los distintos habitantes del planeta. Dicho sucintamente: "las élites son cosmopolitas; la gente, local" (Castells 2000, 493; cf. Huntington 2004, 310-312). De hecho, por un lado, encontramos a los cosmopolitas o globalizados, que matan el espacio y viven en el tiempo (la distancia, p. ej., entre Nueva York y Ámsterdam no la marcan los más de cinco mil kilómetros que separan ambas ciudades, sino las siete horas del viaje en avión); y, por otro, a los provincianos o localmente sujetos, que matan el tiempo como pueden y viven sin elección en un espacio acotado previamente ${ }^{11}$. De este modo, como afirma Bauman $(2001,8)$, "la libertad de movimientos, una mercancía siempre escasa y distribuida de manera desigual, se convierte rápidamente en un factor de estratificación en nuestra época moderna tardía o posmoderna"12.

En principio, el derecho internacional vigente reconoce a cualquier persona el derecho de abandonar el Estado del que es ciudadano y de retornar a él (DUDH, art. 13.2), pero no se contempla, sin embargo, el correlativo derecho a ser aceptado por otro Estado. Esto representa una enorme paradoja, pues si es un derecho absoluto de toda persona poder abandonar su propio país, los Estados tendrían entonces el deber de admitir a quienes optan por ejercerlo (cf. Dummett 1998, 63). En la práctica, esta regulación conduce, pues, a un notable desajuste entre el reconocimiento irrestricto de la libertad emigratoria y el sometimiento fáctico del derecho a inmigrar a la soberanía de los países receptores. $Y$ es más, esta reglamentación asimétrica entre emigración e inmigración supone una injustificada restricción del derecho a la libre circulación de los seres humanos (tanto del ius communicationis que Francisco de Vitoria defendiera ya en el siglo XVI, como del derecho/deber de hospitalidad universal que Immanuel Kant preconizara en el XVIII). ¿Cómo puede defenderse que negar la entrada a un país no supone una violación palmaria de un derecho humano elemental? Sin embargo, aún sigue siendo una prerrogativa exclusiva de todo Estado que se precie decidir a quién admite en su territorio. Abolir o al menos limitar esta prerrogativa sería un paso importante para lograr configurar una ciudadanía cosmopolita y ubicarse en el horizonte normativo de una teoría global de la justicia. Este paso precisaría indudablemente de una nueva comprensión de la soberanía estatal, pues, de acuerdo con este principio, es práctica común en las relaciones internacionales defender que ningún Estado u organismo internacional está facultado a entrometerse en los asuntos internos de otros Estados y, menos aún, a inmiscuirse en el modo en que trata en su territorio a sus propios ciudadanos y, ya no digamos, a aquéllos que no lo son. Sin embargo, el hecho de ser ciudadano de un determinado Estado no excluye a nadie de ser miembro del género humano ni de la ciudadanía universal.

Para asegurar que la institución de la ciudadanía pueda desempeñar realmente una función inclusiva y pueda servir de vía de entrada en la comunidad política en la que se reside legalmente debería estar desvinculada de la pertenencia a una determinada comunidad nacional. Esta institución tendria entonces que estar articulada en términos postna- 
cionales o transnacionales: una ciudadanía entendida como una condición de todo individuo, conforme a la cual uno tiene derechos y obligaciones en cualquier lugar del planeta en donde se encuentre (cf. Velasco 2005, 47-49). Una ciudadanía así concebida se fundaría en la pertenencia real a un espacio compartido de interacción social, de la cual la residencia legal puede ser un buen indicio, y no en cualquier suerte de particularismo étnico-cultural de vinculación a un grupo determinado. La titularidad de una misma ciudadanía se ha de extender a todos aquellos que comparten dicho espacio y adecuar asi el demos a la población efectiva. Se trata de redefinir o resignificar en términos inclusivos la categoría de ciudadanía de modo que quede desligada doctrinal y normativamente de la nacionalidad y vinculada funcionalmente a la residencial legal.

Lo dicho en el párrafo anterior no se inscribe en el género utópico. En las últimas décadas, como observa Samuel Huntington $(2004,241)$, se ha ido abriendo paso una "nueva concepción de la ciudadanía, según la cual ésta no es un status de carácter nacional conferido por el Estado a los individuos, sino un derecho transnacional de los individuos frente a los Estados que aquéllos Ilevan consigo allá donde decidan residir" (cursivas de JCV). Esta observación es relevante dada la evidente animadversión que este autor muestra ante esta supuesta devaluación de la ciudadanía nacional. Desde otros espectros ideológicos bien diferentes se coincide además en la misma constatación: "Uno de los avances más sorprendentes de finales del siglo XX en el campo de la inmigración fue lo mucho que se redujeron las distinciones legales entre ciudadanos y residentes no ciudadanos" (Carens 2004, 399). El progresivo reconocimiento de derechos a los inmigrantes con residencia legal conduce a la afirmación por parte de los Estados receptores de una forma de cuasiciudadanía, a la que Hammar (1990) denominó denizenship. La norma, en todo caso, ya no es una noción indivisible de ciudadanía, como única figura receptora de los derechos, sino cada vez más una concepción flexible de la misma (cf. Ong 1999; Bauböck 2004; Benhabib 2005). En esta labor de promoción de los derechos de los inmigrantes, las normas jurídicas internacionales han jugado y juegan un destacado papel: están logrando que se reconozca que cualquier individuo posee en cualquier lugar que se encuentre un status jurídico internacional y con ello todo un repertorio normativo de derechos que le ampara con independencia de la nacionalidad que ostente y de la voluntad de los distintos gobiernos ${ }^{13}$. A la vez que se ha ido reduciendo el potencial discriminador de la nacionalidad, ha ido tomando forma una incipiente ciudadanía mundial. Es éste un fenómeno cuyo valor es preciso ponderar, pues tanto la emergencia de ésta como, sobre todo, la creciente tolerancia, e incluso aceptación explícita, de la doble nacionalidad (cf. Faist y Gerdes 2006) entran en abierta contradicción con la concepción hasta hace poco hegemónica de la ciudadanía como pertenencia única y exclusiva en una determinada comunidad política.

Aunque en general se observan avances en la equidad de trato concedido a los inmigrantes, subsisten algunas brechas significativas entre los derechos atribuidos a los ciudadanos y a los residentes legales, particularmente en materia de derechos políticos. Especialmente sangrantes son, con todo, aquellas otras que separan a estos dos grupos, situados ambos al amparo del derecho, de los metecos de nuestra época: los sans papiers. Su proliferación es, en realidad, una secuela de otros tiempos. Es a partir de la aparición de los Estados nacionales cuando se generaliza la exigencia de documentos oficiales para viajar ${ }^{14}$. La consecuencia inmediata de su puesta en marcha es la multiplicación de apátridas y personas indocumentadas. En este contexto, el estar literalmente sin papeles estigmatiza y sitúa a las personas al margen del sistema social y de las instituciones públicas. El punto culminante de esta delirante política de exclusión es la reclusión de las personas extranjeras desprovistas de los permisos administrativos requeridos en centros de internamiento mientras se tramitan los procesos de repatriación. Tales centros son la expresión máxima de la normalización paradójica de un estado de excepción en el marco de sociedades formalmente democráticas (cf. Zamora 2005).

El hecho de que se hayan modificado en muchos países las condiciones de permanencia de los migrantes y que estos cambios sean, en ciertos casos, para adaptarse a las exigencias de los derechos humanos, no significa, lamentablemente, que se hayan transformado también las condiciones de entrada en la misma dirección. Por el contrario, en las últimas décadas ha ido surgiendo un nuevo orden migratorio internacional, un orden presidido sobre todo por la generalización de políticas restrictivas para el movimiento de personas, un orden que responde a la dinámica que bien puede ser calificada de globalización fronterizada (cf. Arango 2007). En nuestros días, las restricciones son la regla y la libertad de circulación, la

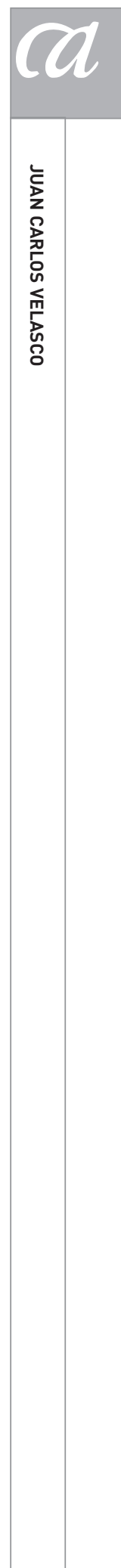


excepción. La insistencia en aplicar políticas migratorias restrictivas, que a la postre devienen en un intento imposible de controlar, cerrar e incluso blindar las fronteras, responde a una comprensión de los flujos migratorios como si en definitiva obedecieran a una dinámica unilateral procedente del exterior y no a una compleja red de intensas relaciones multilaterales de carácter no sólo económico, sino también sociocultural.

Por el contrario, que los inmigrantes indocumentados o en situación irregular dentro de un territorio estatal fueran tratados como titulares de derechos constituiría un signo palpable de que los derechos humanos habian sido tomados en serio y que ello implica reconocer a todos los humanos como sujetos de derechos y atribuirles, por ende, un código mínimo, pero inviolable. De lo que ahora se trataría es de extender también a esas personas indocumentadas o en situación irregular el universalismo inherente de los derechos humanos ${ }^{15} y$ otorgar rango de oficialidad a esas tendencias hacia la desnacionalización de la ciudadanía que van abriéndose paso y que, en gran medida, son coherentes con la creciente toma de conciencia acerca de la necesidad de limitar la soberanía estatal en lo referente a la definición de las "fronteras de la comunidad nacional" (cf. Benhabib 2005). Las modificaciones normativas que plasmen esas exigencias universalistas de los derechos hu- manos precisan, sin duda, el establecimiento de algún tipo de organización mundial que vele por su protección efectiva e integral (tal como ya se ha señalado en el anterior apartado). También se ha avanzado en este respecto y se va abriendo paso la necesidad de un auténtico constitucionalismo internacional o, si se prefiere, de que emerja una instancia jurídico-política a escala planetaria.

Si se busca realmente la protección integral de los derechos humanos, incluidos también los derechos humanos de los inmigrantes, se requiere impulsar acciones internacionales concertadas. Si la globalización en su última fase se nos es presentada ante todo como una superación de las barreras a la comunicación, ya es hora de que se entienda también como una superación de las fronteras políticas. Aunque no es nada seguro que los gobiernos nacionales estén tomando debida conciencia de ello, la facticidad de la globalización y la validez universal de los derechos humanos están posibilitando la emergencia de elementos de un nuevo discurso sobre los derechos humanos y con él un nuevo marco para las reivindicaciones sociales. No en vano, los procesos de globalización son procesos de desnacionalización que permiten la configuración de un escenario mundial unificado. Un discurso que también ha de encontrar su específica plasmación en el ámbito de las políticas públicas sobre materia migratoria.

\section{NOTAS}

1 La categoria migrantes resulta más abarcadora que las de inmigrantes y emigrantes, pues tiene la ventaja de poner de relieve el carácter cambiante del punto de referencia de los movimientos migratorios, por un lado, y los vinculos transnacionales que sus actores mantienen de manera duradera entre las sociedades de origen y las de destino, por otro (cf. Velasco 2009).

2 El punto de partida de la explicación rawlsiana de la pobreza y el hambre exclusivamente en términos de factores causales internos de las sociedades donde ocurren -hábito metodológico que Pogge $(2005,181-186)$ califica como nacionalismo explicativo- es una suposición que desgraciadamente no siempre encuentra correlato en la realidad social, a saber: "el derecho de gentes presume que cada sociedad tiene, en su población, un conjunto suficiente de capacidades humanas para establecer instituciones justas" (Rawls 2001, 138).

3 Cuestionar que la pobreza mundial responda exclusivamente a causas endógenas de carácter político-institucional no implica negar que éstas puedan tener un peso especifico. Cabe argumentar, por ejemplo, que la negación de los derechos de participación política en un país obstaculiza la movilización de la opinión públi-

Aceptado: 24 de noviembre de 2009 
ca y la reclamación de la puesta en marcha de medidas adecuadas para la generación y el reparto equitativo de la riqueza.

4 Entre la multitud de datos, uno de los más elocuentes quizás sea éste: las 225 personas más ricas del planeta disponen de los mismos recursos que el $47 \%$ más pobre. Otros datos igualmente alarmantes: 2.500 millones de personas viven con menos de dos euros al día y todos los días 850 millones de personas pasan hambre (Human Development Report 2005 - PNUD).

5 La intensificación de los flujos migratorios hacia los países desarrollados experimentada en las dos últimas décadas, percibida por la opinión pública de los mismos como una "crisis migratoria", es, en realidad, el resultado de una crisis de las relaciones norte-sur (cf. Castles 2006, 44). No obstante, relevantes flujos contemporáneos toman otros rumbos: "Las corrientes internacionales de mano de obra no han dejado de crecer durante los últimos años, no sólo desde el sur hacia el norte, representadas por los trabajadores e inmigrantes, legales o ilegales, sino también del sur al sur, esto es, las migraciones de obreros temporales o semipermanentes, que se desplazan de una región del sur a otra, como es el caso de los obreros del sur de Asia que se trasladan al Golfo Pérsico" (Hardt y Negri 2002, 150). De lo que se deduce que en el seno del sur también existen un norte y un sur.

6 El potencial de desarrollo de las migración posee una doble dimensión: económica y social. Los migrantes normalmente comparten lo que ganan con sus familias y comunidades de origen. En muchos casos, se trata de dinero en efectivo, conocido como remesas, pero la familia y su entorno pueden beneficiarse de otras maneras: fluyen también unas remesas sociales que contribuyen, por ejemplo, a la reducción de las tasas de fecundidad, al aumento de las tasas de matrícula escolar y al progresivo empoderamiento de las mujeres (cf. PNUD 2009).

7 Carens (1987) arguye con razón que las teorias políticas contemporáneas hegemónicas -sea el libertarismo de Nozick o sea el liberalismo igualitarista de Rawls- no aportan razones morales para restringir el derecho de los extranjeros a entrar en un pais 0 a tomar residencia en él $y_{1}$ sin embargo, proceden como si las hubiera. Detrás de la defensa de la fronteras se escudan con harta frecuencia concepciones colectivistas de la política: "La relevancia moral de las fronteras [...] ha sido siempre el argumento de quienes han intentado poner coto a la vigencia de los derechos humanos aduciendo la necesidad de salvaguardar las peculiaridades nacionales y la identidad colectiva a la que se le atribuye el mismo rango moral que a la autonomía individual" (Garzón 1997, 23). Entre los defensores más conocidos de un cierre de las fronteras (aunque parcial y condicionado) $y$, sobre todo, de impedir o dificultar el acceso a la ciudadanía a los extranjeros, se encuentra Walzer (1993, 44-74). A diferencia de autores como Sartori, el caso de Walzer resulta sumamente inquietante en la medida en que justifica su actitud en base a supuestos criterios de justicia. Su posicionamiento sería deudor de un presupuesto profundamente errado: identificar la asociación política con una comunidad definida en términos étnico-culturales (cf. Benhabib 2005, cap. 3).
8 Éste es precisamente el tema central de un libro en el que ahora me encuentro en la fase final de elaboración: Más que un sueño. Cosmopolitismo y justicia global.

9 Además de la normativa general sobre derechos humanos, para los migrantes económicos es de aplicación, y muy particularmente, la Convención sobre la Protección de los Derechos de todos los Trabajadores Migratorios $y$ de sus Familiares, aprobada en el año 1990, aunque no entró en vigor hasta el 2003. Sin embargo, hasta el año 2009 este instrumento jurídico tan sólo ha sido ratificado por 41 paises, todos ellos países fundamentalmente de emigración ( $y$, eventualmente, de tránsito). El hecho de que no haya sido adoptado por ningún pais receptor importante (y ninguno con un índice de "desarrollo humano muy alto") le resta gran parte de su potencial eficacia. Otros tipos de migrantes, como, por ejemplo, los refugiados (que representan menos del 10\% de los migrantes internacionales, cf. Castles y Miller 2004, 15-16), cuentan con la Convención de Ginebra sobre el Estatuto de los Refugiados (de 1951), que ha sido ratificada por 147 países y pasa por ser por uno de los instrumentos internacionales más efectivos, hecho en el que tiene mucho que ver la labor desplegada por el ACNUR, una de las agencias de la ONU con más medios y prestigio. Con todo, no cabe sostener que la cuestión de los refugiados, ni la de los solicitantes de asilo, esté satisfactoriamente resuelta.

10 La desigualdad y la exclusión social son efectos inseparables de la institución formal de la ciudadanía, pues, al denotar la pertenencia a una comunidad política determinada, quienes no la posean automáticamente 
quedan excluidos de los beneficios y privilegios reservados a los miembros de la comunidad. De este modo, la definición de la ciudadanía "con fundamento en pertenencias nacionales y territoriales representa la última gran limitación normativa del principio de igualdad jurídica" (Ferrajoli 1999, 41).

11 Agradezco esta observación a mi compañero Fernando Bayón.

12 La movilidad valiosa es, obviamente, la elegida, no la impuesta por las circunstancias. Por ello, para quienes se trasladan para huir de una situación desesperada, "la movilidad a través de las fronteras a menudo equivale a una migración forzada en la mayor de las pobrezas [...]. En realidad, en la perspectiva de esas personas, probablemente la necesidad más urgente sea, por el contrario, un lugar estable y definido para vivir, una cierta inmovilidad" (Hardt y Negri 2002, 150).

13 Con independencia del interminable debate acerca de si los derechos humanos son un concepto universal, un concepto típicamente occidental o, más bien, un localismo occidental globalizado (y dejando también al margen el sello occidental de la propia pregunta), el prestigio logrado por la Declaración Universal de Derechos Humanos ha contribuido a consolidar la convicción jurídica de que los Estados soberanos tienen obligaciones ineludibles en materia de derechos humanos con respecto a cualquier individuo que resida en su territorio tenga la nacionalidad que sea (cf. Sassen 2001). Los derechos humanos se han ido erigiendo asi en límites a la discrecionalidad y la soberanía estatales. El amplio reconocimiento internacional de estos derechos representa todo un hito histórico interpretable como un "signo del progreso moral de la humanidad": "Frente a la ambigüedad de la historia, también creo que uno de los pocos signos, quizá el único, de un movimiento histórico creible hacia mejor sea el creciente interés de los estudiosos y de las mismas instancias internacionales por un reconocimiento cada vez mayor, y una cada vez más segura garantía, de los derechos humanos" (Bobbio 1991, 183).

14 Cf. Bauman 2005, 162-164. Desde principios del siglo XIX, los Estados se han mostrado entusiastas a la hora de registrar a sus habitantes y de regular los movimientos de personas dentro y a través de las fronteras. Documentos tales como las tarjetas de identidad, los pasaportes y las visas de entrada, así como los censos y los sistemas de registro de los hogares, son instrumentos cruciales para alcanzar estos objetivos de control de la movilidad. Los Estados -en la medida de sus propias posibilidades- han creado medios exclusivos e inequívocos, y toda una abultada burocracia, con el fin de realizar un registro completo y poder identificar así a todos los individuos, tanto los suyos propios como los de otros Estados (cf. Torpey 2006).

15 La noción de los derechos humanos nos remite "a la 'idea ética' de una comunidad universal, de una civitas maxima de la que todas las personas forman parte" (Zolo 2000, 163).

\section{BIBLIOGRAFÍA}

Álvarez, Daniel (2007): "Ciudadanía y justicia global", en Revista Internacional de Filosofía Política, n. ${ }^{\circ} 29,139-159$.

Appiah, Kwame A. (2007): Cosmopolitismo. La ética en un mundo de extraños [2006], Katz, Buenos Aires.
Arango, Joaquín (2007): "Las migraciones internacionales en un mundo globalizado", en Vanguardia / Dossier, n. ${ }^{\circ} 22,6-17$.

Arendt, Hannah (2001): "Karl Jaspers, ¿ciudadano del mundo?" [1957], en idem, Hombres en tiempos de oscuridad, Gedisa, Barcelona, 89-102.

Barry, Brian (1995): Teorías de la justicia [1989], Gedisa, Barcelona.

Bauböck, Rainer (2004): "Cómo transforma la inmigración a la ciudadania", en G. Aubarell y R. Zapata, eds., Inmigración y procesos de cambio, Icaria, Barcelona, 197-214.

- (2005): "Expansive Citizenship - Voting beyond Territory and Membership", en Political Science \&t Politics, 38 (4), 763-767.

Bauman, Zygmunt (2001): La globalización. Consecuencias humanas [1998], FCE, México.

- (2005): Amor líquido, Buenos AiresMéxico-Madrid, FCE.

Beck, Ulrich (1998): La sociedad del riesgo [1986], Paidós, Barcelona.

Beitz, Charles S. (1979, 1999²): Political Theory and International Relations, Princeton U. P., Princeton.

Benhabib, Seyla (2005): Los derechos de los otros [2004], Gedisa, Barcelona.

Bobbio, Norberto (1991): El tiempo de los derechos, Sistema, Madrid.

Carens, Joseph H. (1987): "Aliens and Citizens: The Case for Open Borders", en Review of Politics, 49, 251-273.

- (2004): "La integración de los inmigrantes", en G. Aubarell \&t R. Zapata, eds., Inmigración y procesos de cambio, Icaria, Barcelona, 393-420.

Castells, Manuel (2000): La era de la información, vol. 1, Alianza, Madrid.

Castles, Stephen (2004): "Globalización e inmigración", en G. Aubarell y R. Zapata, eds., Inmigración y procesos de cambio, Icaria, Barcelona, 33-56.

- (2006): "Factores que hacen y deshacen las políticas migratorias", en A. 
Portes y J. DeWind (coords.): Repensando las migraciones, Miguel Ángel Porrúa, México, 33-66.

Cole, Phillip (2000): Philosophies of exclusion. Liberal political theory and immigration, Edimburgo U.P., Edimburgo.

Dower, Nigel (1995): "La pobreza en el mundo", en P. Singer, ed., Compendio de ética [1991], Alianza, Madrid, 377-390.

Dummett, Michael (2004): Sobre inmigración y refugiados [2001], Cátedra, Madrid.

Dworkin, Ronald (2003): Virtud soberana. La teoría y la práctica de la igualdad [2000], Paidós, Barcelona.

Faist, Thomas y Gerdes, J. (2006): "La doble ciudadanía como un proceso dependiente de la trayectoria", en A. Portes y J. DeWind, coords., Repensando las migraciones, Miguel Ángel Porrúa, México, 97-129.

Ferrajoli, Luigi (1999): Derechos y garantías. La ley del más débil, Trotta, Madrid.

Fraser, Nancy (2008): Escalas de justicia, Herder, Barcelona.

Garzón, Ernesto (1997): "Cinco confusiones acerca de la relevancia moral de la diversidad cultural", en Claves de razón práctica, n. ${ }^{\circ} 74,10-23$.

Giddens, Anthony (2007): Sociología [2006], 5. a ed., Alianza, Madrid.

Habermas, Jürgen (2000): La constelación posnacional [1998], Paidós, Barcelona.

Hardt, Michael y Negri, Antonio (2002): Imperio [2000], Paidós, Barcelona.

Hume, David (1993): Investigación sobre los principios de la moral [1751], Alianza, Madrid.

Huntington, Samuel (2004): ¿Quiénes somos? [2004], Paidós, Barcelona.
Jones, Charles (1999): Global Justice. Defending Cosmopolitism, Oxford U.P., Oxford.

Kymlicka, Will y Norman, Wayne (1997): "El retorno del ciudadano" [1994], en La política, n. 3, 5-39.

Kymlicka, Will (2006): Fronteras territoriales [2001], Trotta, Madrid.

Morris, Lydia (2002): Managing Migration. Civic Stratification and Migrants' Rig$h t s$, Routledge, Londres.

Nagel, Thomas (2005): "The Problem of Global Justice", en Philosophy \& Public Affairs, vol. 33, n. ${ }^{\circ} 2,113-146$.

Nussbaum, Martha (2007): Las fronteras de la justicia [2005], Paidós, Barcelona.

Ong, Aihwa (1999): Flexible Citizenship, Duke U.P., Durham.

PNUD (2009): Informe sobre Desarrollo Humano 2009. Superando barreras: movilidad y desarrollo humanos, Programa de las Naciones Unidas para el Desarrollo, Nueva York, 2009. [Acceso online: http://hdr.undp.org/es/]

Pogge, Thomas (2004): "La incoherencia entre las teorías de la justicia de Rawls", en Revista Internacional de Filosofía Política, n. ${ }^{\circ}$ 23, 28-48.

- (2005): La pobreza en el mundo y los derechos humanos [2002], Paidós, Barcelona.

- (2010): "Migraciones y pobreza" [1997, 2005], en Arbor, n. ${ }^{\circ} 744,571-$ 583.

Rawls, John (1979): Teoría de la justicia [1971], FCE, México.

- (2001): El derecho de gentes [1999], Paidós, Barcelona.

Sassen, Saskia (2001): ¿Perdiendo el control? La soberanía en la era de la globalización, Bellaterra, Barcelona.

- (2003): Contrageografías de la globalización, Traficantes de sueños, Madrid.
- (2006): "La formación de las migraciones internacionales: implicaciones políticas", en Revista Internacional de Filosofía Política, n. ${ }^{\circ} 27$, 19-39.

Seglow, Jonathan (2006): Immigration and Global Justice, en Royal Holloway Department of Politics and International Relationss Working Paper Series, n. ${ }^{\circ} 1$.

Singer, Peter (2003a): Ética práctica [1993²], Cambridge U. P., Madrid.

- (2003b): Un solo mundo. La ética de la globalización [2002], Paidós, Barcelona.

Torpey, John (2006): "Yendo y viniendo. La monopolización estatal de los legítimos 'medios de movimiento'", en Zona Abierta, n. ${ }^{\circ} 116 / 117,59-87$.

Velasco, Juan Carlos (2005): "Estado nacional y derechos de los inmigrantes", en Arbor, n. ${ }^{\circ}$ 713, 37-48.

- (2009): "Transnacionalismo migratorio y ciudadanía en mutación", en Claves de razón práctica, n. ${ }^{\circ} 197$, 32-41.

- (2010): "El giro globalista de la filosofía de la justicia", en Oscar Nudler (ed.), Enciclopedia Iberoamericana de Filosofía, vol. 31, Trotta-CSIC, Madrid (en prensa).

Walzer, Michael (1993): Las esferas de la justicia [1983], FCE, México.

Weblog Migraciones. Reflexiones cívicas http://weblogs.madrimasd.org/migraciones

Zamora, José Antonio (2005): "Políticas de inmigración, ciudadanía y estado de excepción", en Arbor, n. ${ }^{\circ}$ 713, 53-66.

- (2008): Inmigrantes entre nosotros: ¿integración o participación?, Foro I. Ellacuría, Murcia.

Zolo, Danilo (2000): Cosmópolis [1997], Paidós, Barcelona. 